\title{
Draining sterile fluid collections in acute pancreatitis? Primum non nocere!
}

\author{
Marc G. H. Besselink • Hjalmar C. van Santvoort • \\ Olaf J. Bakker • Thomas L. Bollen • \\ Hein G. Gooszen
}

Published online: 7 April 2010

(c) The Author(s) 2010. This article is published with open access at Springerlink.com

With interest we read the randomized study by Zerem et al. [1] regarding the drainage of sterile fluid collections in acute pancreatitis. The authors are to be commended for performing a randomized trial in a difficult patient population.

Nearly all international guidelines advocate conservative management of sterile fluid collections in acute pancreatitis: (a) the American Gastroenterological Association (2007): “Acute fluid collections around the pancreas in the setting of acute pancreatitis require no therapy in the absence of infection or obstruction of a surrounding hollow viscus" [2], (b) the American College of Gastroenterology (2006): "Most peripancreatic fluid collections remain sterile and will disappear during the recovery from acute pancreatitis" [3], and (c) the international consensus meeting on treatment of acute pancreatitis (2004): "Routine operative or percutaneous drainage of the former (...peripancreatic fluid collections and pancreatic necrosis...) is not necessary and may infect otherwise sterile tissues" [4]. Nevertheless, guidelines should be put to the test of evidence-based medicine and accordingly the

On behalf of the Dutch Pancreatitis Study Group.

M. G. H. Besselink ( $₫)$ · H. C. van Santvoort · O. J. Bakker Department of Surgery, University Medical Center Utrecht, P.O. Box 85500, HP G04.228, 3508 GA Utrecht, The

Netherlands

e-mail: m.besselink@umcutrecht.nl

T. L. Bollen

Department of Radiology, St. Antonius Hospital, Nieuwegein, The Netherlands

H. G. Gooszen

Department of Surgery, Radboud University Nijmegen Medical Centre, Nijmegen, The Netherlands authors routinely aspirated peripancreatic fluid collections in 58 patients and subsequently randomized 40 patients with sterile peripancreatic fluid collections. Group A $(n=20)$ received conservative management, whereas group B $(n=20)$ underwent prolonged percutaneous catheter drainage of sterile collections. As the primary end point the authors chose "conversion to more aggressive procedure," which included percutaneous catheter drainage and surgery. In group A, 11 patients required additional treatment (mostly percutaneous drainage, $n=8$ ), whereas in group B three patients required surgical intervention (11/ 20 vs. $3 / 20, P=0.02$ ). The authors concluded that "prolonged catheter drainage is more effective for management of recurrent sterile fluid collections in acute pancreatitis than is conservative management".

We consider the primary end point of "conversion to more aggressive procedure" rather inappropriate. Why not study clinically relevant outcome measures such as mortality, organ failure, secondary infection of peripancreatic collections, length of hospital stay, or a composite of these events? Notably, it is our interpretation, in line with the definition of the author's primary outcome measure, that all patients in group B underwent an "aggressive procedure," that being percutaneous drainage! Along this line of reasoning, all 20 patients in group B had an interventional procedure versus 11 of 20 patients in group A $(P=0.001)$. Furthermore, the prolonged percutaneous drainage in group $B$ led to a significant increase in infected collections (4 vs. $11, P=0.048$ ), that became fatal in one patient.

In conclusion, is the conservative strategy not to be considered the superior strategy? The conservative strategy, compared to prolonged catheter drainage, (1) reduces the risk of requiring an intervention by $55 \%$ ( $9 / 20$ vs. 20/20 patients) and (2) reduces the risk of infection by 35\% (4/20 vs. $11 / 20$ patients) without a noticeable negative impact on 
hospital stay and mortality. Previous studies have already demonstrated that percutaneous drainage of sterile collections is associated with increased risk of infections. Walser et al. [5] demonstrated that the risk of infecting sterile collections with catheter drainage is $59 \%$ (13/22 patients) vs. $20 \%$ (3/15 patients) in collections that were only aspirated.

In most experienced centers worldwide, sterile fluid collections are treated conservatively, in accordance with international guidelines. Unnecessary aspiration and/or drainage of sterile collections increases the risk of secondary infection with the subsequent need for surgical intervention and, ultimately, increased mortality.

Disclosures Drs. Besselink, Van Santvoort, Bakker, Bollen, and Gooszen have no conflicts of interest or financial ties to disclose. The Dutch Pancreatitis Study Group also has no interests or financial ties to disclose.

Open Access This article is distributed under the terms of the Creative Commons Attribution Noncommercial License which permits any noncommercial use, distribution, and reproduction in any medium, provided the original author(s) and source are credited.

\section{References}

1. Zerem E, Imamovic G, Omerovic S, Imsirovic B (2009) Randomized controlled trial on sterile fluid collections management in acute pancreatitis: should they be removed? Surg Endosc 23:2770-2777

2. American Gastroenterological Association (AGA) Institute on "Management of Acute Pancreatitis" Clinical Practice, Economics Committee, AGA Institute Governing Board (2007) AGA Institute medical position statement on acute pancreatitis. Gastroenterology 132:2019-2021

3. Banks PA, Freeman ML (2006) Practice guidelines in acute pancreatitis. Am J Gastroenterol 101:2379-2400

4. Nathens AB, Curtis JR, Beale RJ, Cook DJ, Moreno RP, Romand JA, Skerrett SJ, Stapleton RD, Ware LB, Waldmann CS (2004) Management of the critically ill patient with severe acute pancreatitis. Crit Care Med 32:2524-2536

5. Walser EM, Nealon WH, Marroquin S, Raza S, Hernandez JA, Vasek J (2006) Sterile fluid collections in acute pancreatitis: catheter drainage versus simple aspiration. Cardiovasc Intervent Radiol 29:102-107 